\title{
Indirect comparison of azacitidine and decitabine for the therapy of elderly patients with acute myeloid leukemia: a systematic review and network meta-analysis
}

\author{
Bingbing Wen ${ }^{1}$, Weiwen You $^{2}$, Sitian Yang ${ }^{2}$ and Xin Du²
}

\begin{abstract}
Background: The DNA hypomethylating agents (HMAs) decitabine and azacitidine have been widely used in the management of elderly patients with acute myeloid leukemia (AML). However, no direct clinical trials have been carried out to compare the two agents. A systematic review and network meta-analysis were performed to indirectly compare the efficacy and safety of decitabine and azacitidine in elderly AML patients.

Methods: We systematically searched PubMed, Medline, Web of Science, Embase and Cochrane Library through May 14, 2019. Randomized controlled trials on elderly AML patients comparing the efficacy and safety between decitabine and azacitidine, or comparing one of HMAs to standard supportive care or placebo were selected. The major outcomes of interest were performed with methods of adjusted indirect comparison and the fixed effect model.

Results: Only three RCTs including a total number of 1086 patients were identified. Direct comparisons showed that azacitidine significantly reduced mortality $(\mathrm{RR}=0.90,95 \% \mathrm{Cl} 0.83-0.97)$ while decitabine was not significantly associated with lower mortality $(\mathrm{RR}=0.97,95 \% \mathrm{Cl} 0.92-1.02$ ) compared to the conventional care regimen (CCR). In addition, for the indirect method, azacitidine significantly reduced mortality compared to decitabine $(\mathrm{RR}=0.8395 \% \mathrm{Cl} 0.77$ $0.90)$ and was more likely to improve complete response (CR) $(R R=1.66,95 \% \mathrm{Cl} 1.17-2.35$, low-certainty evidence). No statistical significance was found for the other studied outcomes.

Conclusions: Compared to CCR, decitabine and azacitidine can promote studied outcomes in elderly AML patients. Indirect evidence with low certainty was used to compare these two agents. The superiority of either agent cannot be confirmed, and head-to-head clinical trials are still required.
\end{abstract}

Keywords: Azacitidine, Acute myeloid leukemia, Elderly patients, Decitabine, Network meta-analysis

\section{Background}

Acute myeloid leukemia (AML), characterized by the expansion of clonal myeloid cells in the bone marrow and peripheral blood, is a heterogeneous haematologic

\footnotetext{
*Correspondence: duxingz@medmail.com.cn

${ }^{2}$ Department of Hematology, Shenzhen Second People's Hospital, The First Affiliated Hospital of Shenzhen University, 3002 Sungang West Road, Futian District, Shenzhen 518000, China

Full list of author information is available at the end of the article
}

malignancy with clinical manifestations of anaemia, haemorrhage and infection [1]. The majority of AML cases are elderly patients with a median diagnosed age of 67 years presented by the SEER Cancer Statistics Review [2]. However, poor prognosis and limited treatments for elderly patients account for the largest number of annual deaths especially for those with comorbidities and poor performance status [3]. The annual incidence rates of AML since from 2010 have been are consistently higher than 4.2 per 100,000 per year [4-8]. The 2- and 5-year

c) The Author(s) 2020. This article is licensed under a Creative Commons Attribution 4.0 International License, which permits use, sharing, adaptation, distribution and reproduction in any medium or format, as long as you give appropriate credit to the original author(s) and the source, provide a link to the Creative Commons licence, and indicate if changes were made. The images or other third party material in this article are included in the article's Creative Commons licence, unless indicated otherwise in a credit line to the material. If material is not included in the article's Creative Commons licence and your intended use is not permitted by statutory regulation or exceeds the permitted use, you will need to obtain permission directly from the copyright holder. To view a copy of this licence, visit http://creativeco mmons.org/licenses/by/4.0/. The Creative Commons Public Domain Dedication waiver (http://creativecommons.org/publicdomain/ zero/1.0/) applies to the data made available in this article, unless otherwise stated in a credit line to the data. 
overall survival (OS) rates of elderly AML patients are approximately $10 \%$ and $2 \%$, respectively [9-11]. Expert bodies, such as the National Comprehensive Cancer Network (NCCN) and European Leukemia Net (ELN), suggest recommended regimens for older and less fit AML patients, including azacitidine and decitabine as one of the options $[12,13]$.

Hypomethylating agents (HMAs), including decitabine and azacitidine, are pyrimidine nucleoside analogues of cytidine and have been approved to treat the AML patients by the Food and Drug Administration (FDA). The use of HMAs is still a common method for those AML patients who are unfit to receive intensive treatment or haematopoietic stem cell transplant (HSCT) [14]. Superior responses have been proven both with azacitidine and decitabine compared to supportive care alone [15-17]. However, direct comparison of these two agents has not been performed in a randomized trial, and the selection of treatments of two agents is still a dilemma for patients and physicians. Therefore, the objective of this study was to compare the efficacy and safety of azacitidine and decitabine in elderly AML patients by performing a systematic review and network meta-analysis.

\section{Methods}

This systematic review and meta-analysis follow the guidelines of Preferred Reporting Items for Systematic Reviews and Meta-Analyses (PRISMA) [18].

\section{Search strategies}

We systematically searched all studies published electronically in Medline, PubMed, Web of Science, Cochrane Library and Embase through May 14, 2019, without time or language restrictions. The keywords we used in the research were: "acute myeloid leukemia," "azacitidine," "decitabine," "elderly patients," and "randomized controlled trial." Two study researchers designed and performed the search strategy (Additional file 1: Table S4).

\section{Eligibility criteria}

Only randomized controlled trials (RCTs) were selected in our systematic review and network-meta analysis. A trial that investigated elderly patients diagnosed with acute myeloid leukemiaand included treatment with azacitidine or decitabine, and compared the two drugs against each other, or compared them to standard supportive care, or placebo was selected. In addition, at least one of the relevant outcomes should be reported in the trial including: mortality, complete and partial responses, and haematologic improvement. We excluded review articles and nonrandomized control trials.

\section{Study selection}

Two review authors screened all the titles and abstracts of trials independently and indicated the eligibility based on inclusion and exclusion criteria. Full text articles and their relevant references were selected for further assessment. Disagreements were settled by discussion of the two review authors and involved a third independent reviewer if necessary.

\section{Data extraction}

Two reviewer authors (BW and WY) extracted data independently from the included studies including study characteristics, participant information of participants, intervention, and interesting outcomes. Disagreements were settled by discussion of the two reviewers. All data were recorded in Microsoft Excel (2016).

\section{Methodologic quality and risk of bias}

Based on the Cochrane Collaboration's tool, the methodological quality of included trials and risk of bias were evaluated by two review authors, which included seven domains: allocation concealment, random sequence generation, incomplete outcome data, selective outcome reporting, blinding of participants and personnel, blinding of outcome assessment and other bias. The risk of bias was rated as high, unclear, or low. Two review authors (BW, WY) evaluated the risk of bias in each trial independently and disagreements were settled by discussion with co-authors.

\section{Quality of evidence}

The quality of evidence, also called certainty in evidence, was evaluated with the GRADE (Grading of Recommendations, Assessment, Development and Evaluation) working group. There were four levels of quality of evidence: very low, low, moderate, and high. Randomized control trials were regarded as high quality but could be downgraded due to indirectness, inconsistency, imprecision, risk of bias and publication bias [19].

\section{Statistical analysis}

All the network meta-analyses (NMAs) were performed by using STATA 14.0 software (Stata Corporation, Texas) and Review Manager 5.3 software (Cochrane Collaboration, Oxford, UK). The binomial distribution was used to calculate and express with relative risks (RRs) and a 95\% confidence intervals (95\% CIs). Because the number of trials was less than 3 and the potential heterogeneity was set among studies, Mantel and Haenszel (M-H) fixed effects models were carried out, and $\mathrm{I}^{2}$ was used to detect the heterogeneity [20]. $I^{2}$ statistics greater than $50 \%$ 
represent substantial statistical heterogeneity. The graph and summary of risk of bias were created to assess the bias within studies.

The adjusted indirect comparisons were performed with Relative Risk (RRs) and 95\% Confidence Interval (CIs) to assess indirect comparisons of two agents [21]. We used the surface under the cumulative ranking (SUCRA) probabilities to rank the treatments for an outcome [22, 23]. For the survival outcome of elderly patients with AML, the largest SUCRA scores might indicate the best intervention.

\section{Results}

\section{Included studies}

A total of 961 records were obtained with the electronic search strategy. After removing duplicates, 582 articles were screened by title and abstract. A total of 516 trials were excluded due to ineligibility and 55 citations were included for full-text analysis. Finally, three trials were eligible for extraction for this network meta-analysis (Fig. 1). The AML network plot was shown in Fig. 2.

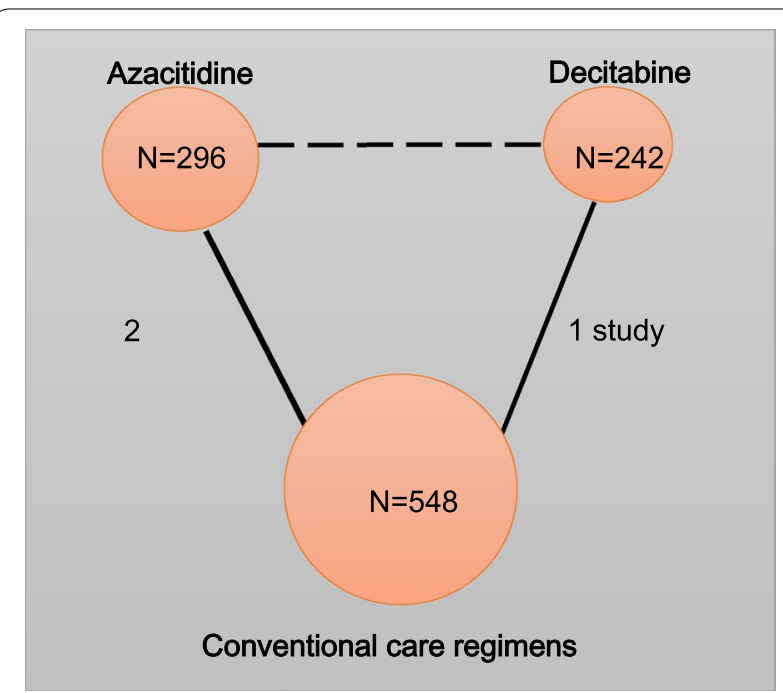

Fig. 2 Network plots of the AML network. Nodes are weighted according to the total number of patients in the included studies. The dashed line represents indirect evidence. Solid lines represent direct evidence

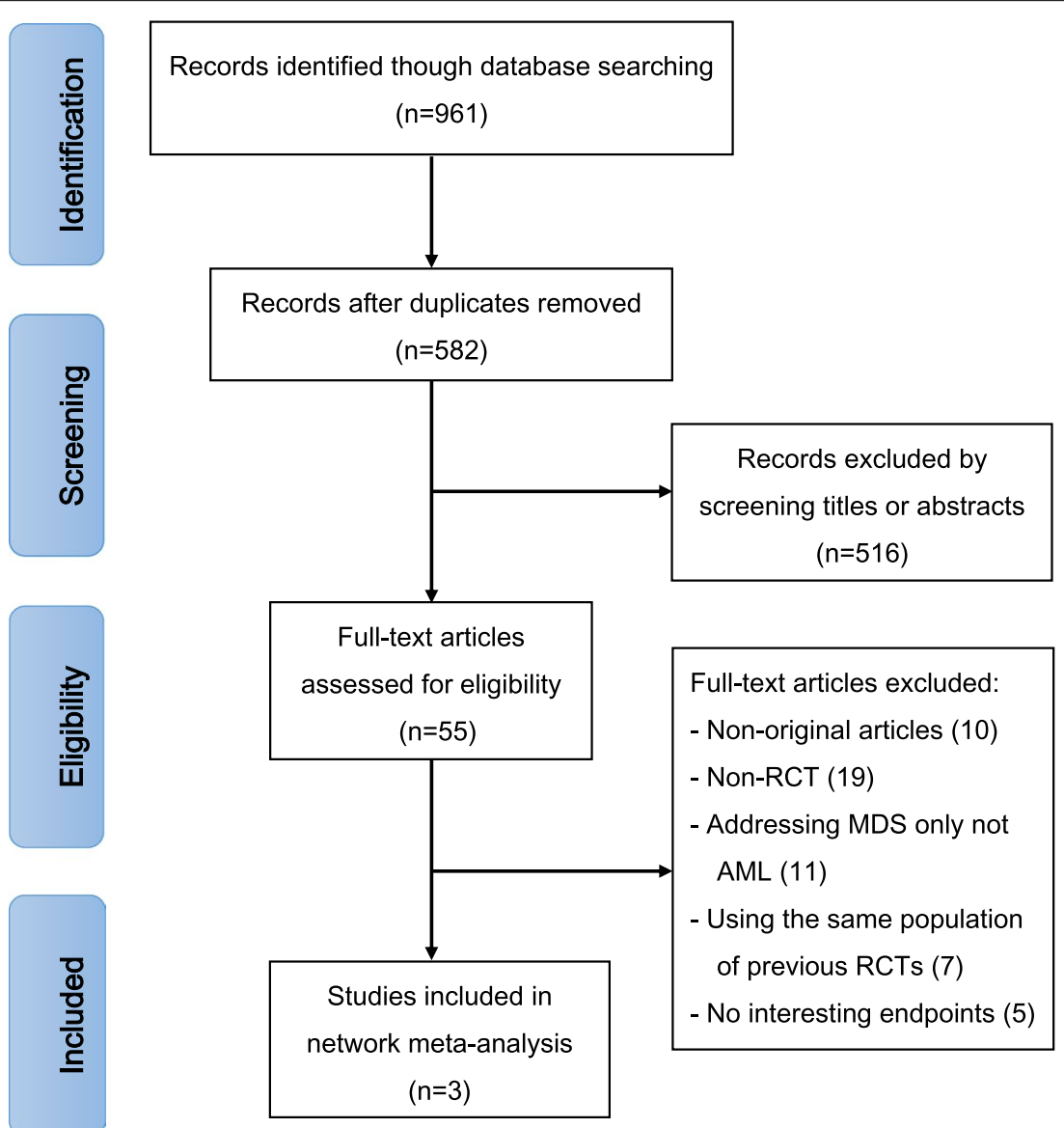

Fig. 1 Flowchart presenting the steps of the literature search and selection 


\section{Study characteristics}

The three RCTs involved a total number of 1086 patients with an age range of 64-91 years old. Two RCTs compared of azacitidine $\left(75 \mathrm{mg} / \mathrm{m}^{2} /\right.$ day, $\mathrm{SC} \times 7$ days $)$ and the conventional care regimens (CCR), including lowdose cytarabine (LDAC) or best supportive care (BSC) or intensive chemotherapy (IC), and included 601 patients (296 azacitidine and 305 CCR; age average 74; range 64-91 years old). The other RCT compared decitabine $\left(20 \mathrm{mg} / \mathrm{m}^{2}, \mathrm{IV}, \mathrm{QD} \times 5\right.$ days $/ 4$ weeks $)$ to the CCR including supportive care or cytarabine and included 485 patients (242 decitabine and 243 CCR; age average 73; range 64-91 years old) (Table 1).

\section{Outcomes}

Direct comparisons showed that azacitidine significantly reduced mortality $(\mathrm{RR}=0.90,95 \%$ CI $0.83-0.98$, $\mathrm{p}<0.001, \mathrm{I}^{2}=94.0 \%$ ) (Additional file 1: Figures S1 and S2), while decitabine did not show improvement in mortality rates compared to CCR $(\mathrm{RR}=0.97,95 \% \mathrm{CI}$ 0.92-1.02) (Additional file 1: Figures S3 and S4). Higher complete responses were reported in both groups as compared to CCR. In addition, indirect head-to-head comparisons showed that azacitidine significantly reduced the mortality rate $(\mathrm{RR}=0.8395 \% \mathrm{CI} 0.77-0.90$, $\left.\mathrm{I}^{2}=82.8 \%\right)$ and anemia ( $\mathrm{RR}=0.68,95 \%$ CI $0.52-0.90$, $\left.\mathrm{I}^{2}=82.2 \%\right)$. Patients in the azacitidine group were more likely to achieve complete response (CR) compared to decitabine $\left(\mathrm{RR}=1.66,95 \%\right.$ CI $1.17-2.35, \mathrm{I}^{2}=65.3 \%$, low certainty) (Fig. 3). There was no statistically significant difference found in other study outcomes including partial response rate, neutropenia and thrombocytopenia. Similarly, azacitidine showed improved overall survival by SUCRA analysis compared to decitabine $(74.7 \%$ vs. 47.1\%) (Fig. 4).

\section{Methodologic quality and risk of bias}

The risk of bias among studies was categorized as low, unclear, or high to its ranking. All the trials were unclear as for random sequence generation. Allocation concealment and blinding of outcome assessment were both achieved in the two trials, whereas blinding of participants and personnel was not conducted in the same trials due to the open label design. In addition, selective reporting and incomplete outcome data were low risk in all trials. The graph and summary of the risk of bias are shown in Fig. 5.

\section{Certainty in evidence}

The unclear risk of bias was shown in all outcomes of the included studies and publication bias could not be explored because of the small number of the trials for direct comparisons, which results in downgrading the certainty. Therefore, low or moderate of the certainty in evidence was found for various outcomes to support the efficacy and safety of azacitidine or decitabine compared to conventional care regimens (Fig. 3 and certainty in the evidence Additional file 1: Tables S1-S3). Similarly, with imprecision and unclear risk of bias, low certainty for various outcomes was performed in head-to-head comparison. The consistency of the network could not be evaluated because there were no closed loops.

\section{Discussion}

In our systematic review and network meta-analysis, three RCTs including 1086 patients were included. Treating patients with azacitidine or decitabine provided improved outcomes in terms of mortality, overall response rate, and improvement in haematological parameters. Indirect head-to-head comparison, with low certainty in evidence, showed that azacitidine was superior to decitabine in terms of the overall survival.

HMAs are still common methods for elderly AML patients who are unfit for intensive therapy or HSCT [24]. NCCN recommendations list treatment with azacitidine and decitabine for elderly patients with newly diagnosed AML as an option [13]. Tapan et al. [25] showed that decitabine could enhance outcomes in elderly AML patients (CR/CRi rate and median of OS were $27 \%$ and 8.6 months, respectively). Furthermore, a randomized study conducted by Yanis Boumber et al. suggested decitabine rather than conventional care regimens for maintenance treatment in AML patients with complete remission, and the OS rates in the decitabine and CCR groups were $45 \%$ and $36 \%$, respectively) [26]. A recent study showed no difference in safety and efficacy between the 5-day decitabine treatment and the 10-day decitabine treatment in elderly patients with AML [27]. Similarly, compared to CCR, Seymour et al. [28] in 2017 suggested that azacitidine could enhance clinical outcomes in elderly AML patients with myelodysplasiarelated changes. In this study, direct comparison showed that the use of either azacitidine or decitabine resulted in lower mortality and higher complete responses compared to CCR, which are consistent with the results of the above trials.

However, no randomized trial has been ever conducted directly to compare azacitidine and decitabine in elderly AML patients. Mehra et al. [29] recently conducted an analysis of comparable survival outcomes and showed that the median OS of decitabine or azacitidine used for frontline treatment in elderly AML patients who were unfit for intensive chemotherapy was comparable. In this study, low certainty of the evidence was found when comparing azacitidine and decitabine. The different baseline characteristics of the studies may have influenced the 


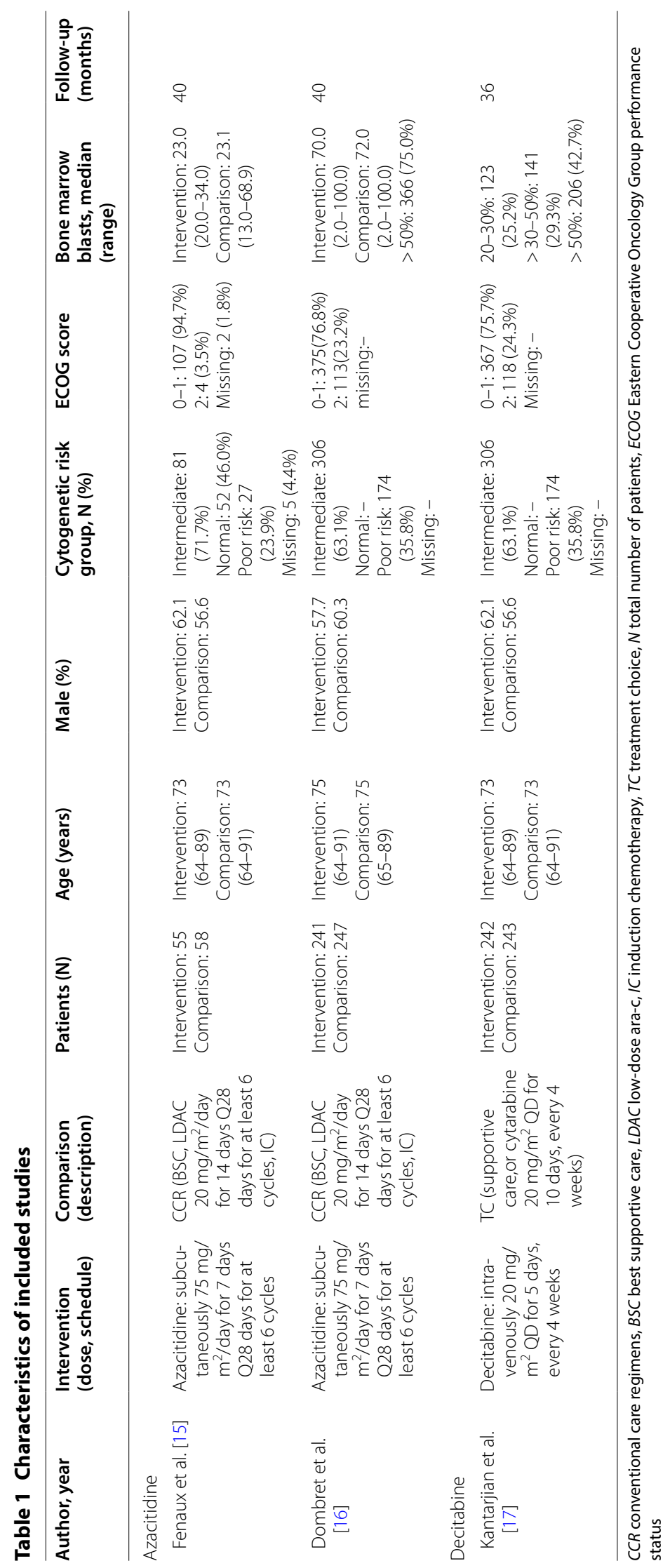




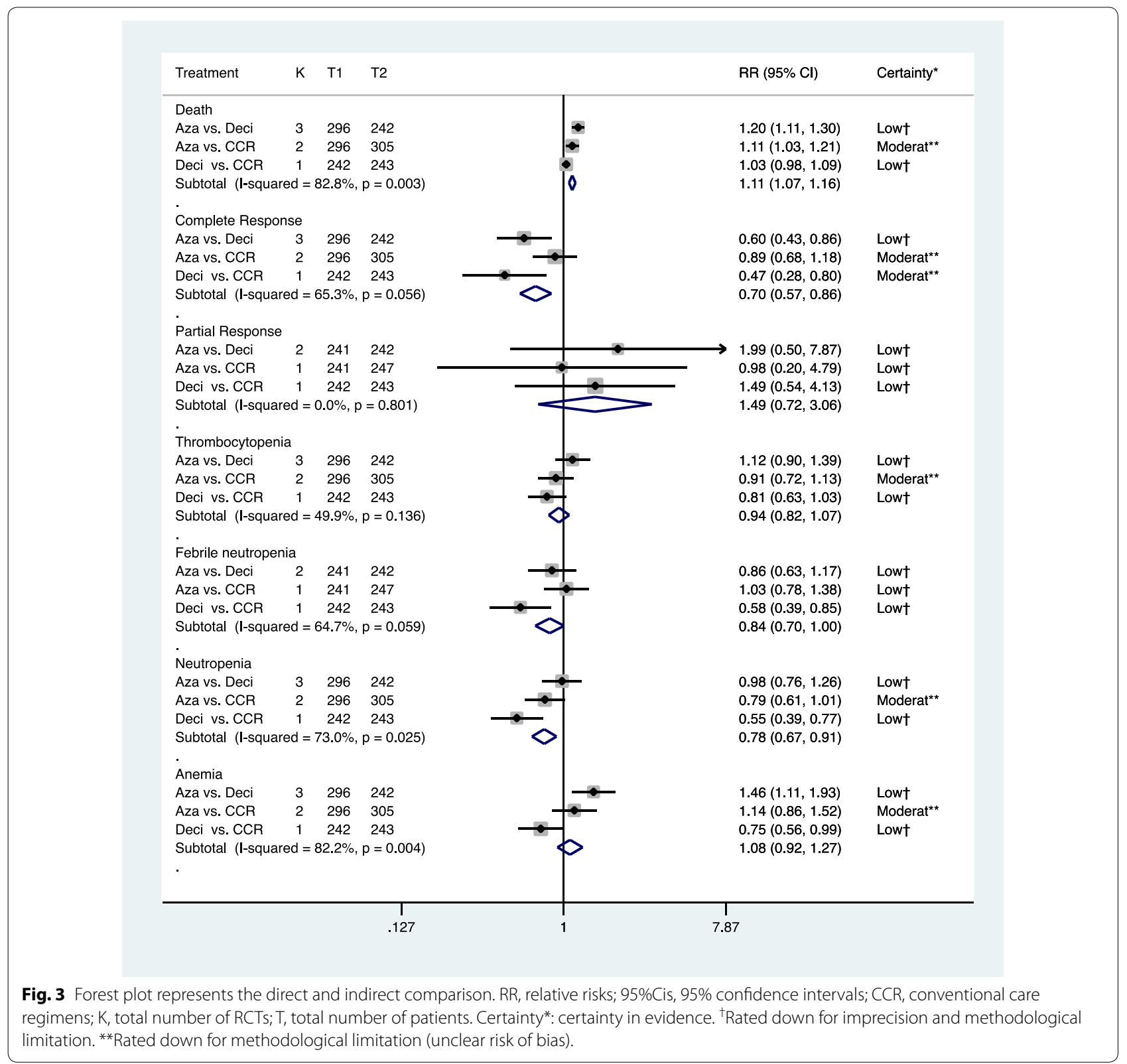

different results of the trials. Many oncology providers still sometimes face dilemmas when deciding between different hypomethylating agents. Furthermore, factors including preferences of patients, adverse effects, and cost can be taken under consideration in the final therapy of two agents. 


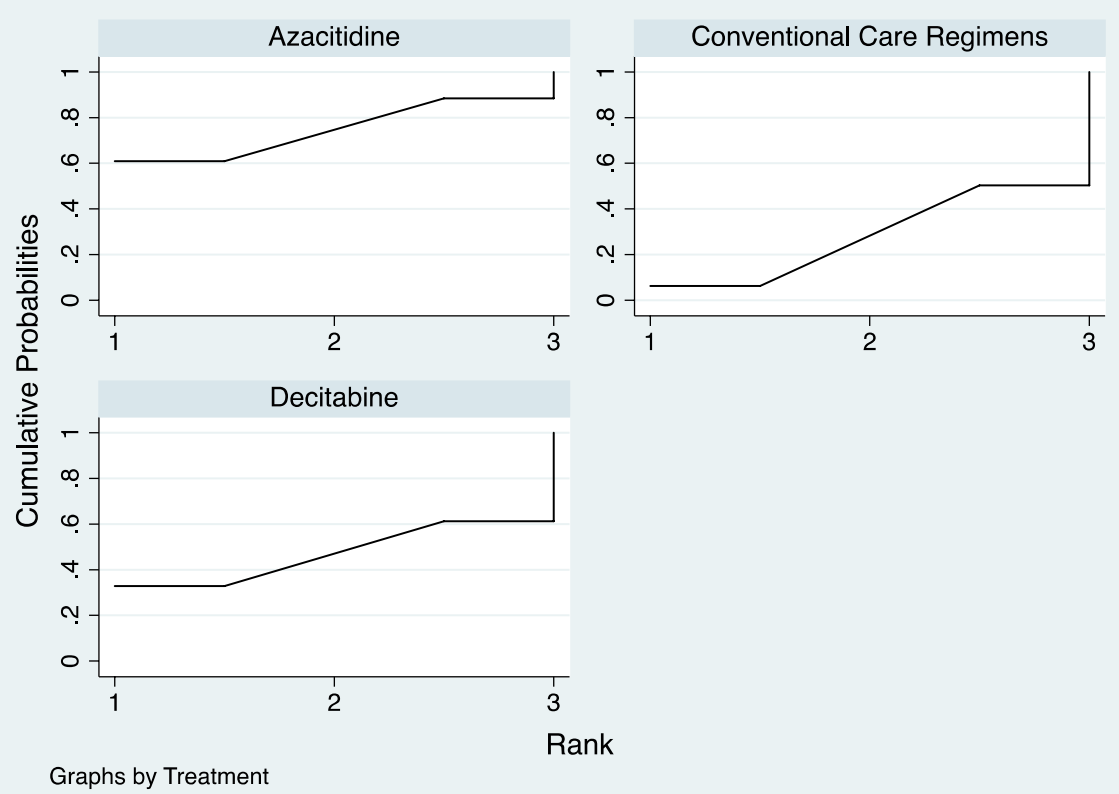

\begin{tabular}{|l|l|l|l|}
\hline Treatment SUCRA ${ }^{*} P$ & SUCRA*Probabil & $\begin{array}{l}\text { Probability as } \\
\text { best }\end{array}$ & Mean Rank \\
\hline $\begin{array}{l}\text { Conventional Care } \\
\text { Regimens }\end{array}$ & 28.3 & 6.2 & 2.4 \\
\hline Decitabine & 47.1 & 32.9 & 2.1 \\
\hline Azacitidine & 74.7 & 60.9 & 1.5 \\
\hline
\end{tabular}

* Surface under the cumulative ranking curve

Fig. 4 The surface under the cumulative ranking curves for survival outcome

\section{Limitations}

There were some limitations in this study. The consistency of the network could not be evaluated because there were no closed loops. Heterogeneity and publication bias could not be obtained because of the small number of trials investigating each agent. In addition, direct and indirect head-to-head comparisons were performed with low or moderate of the certainty of the evidence. Subgroup analysis could not be assessed due to the paucity of data.

\section{Conclusions}

Compared to CCR, azacitidine or decitabine yields both better outcomes, including mortality, overall response, and improvement of haematological parameters. For indirect head-to-head comparisons, low certainty of evidence was found when comparing azacitidine and decitabine. The superiority of either agent cannot be confirmed in this study and head-to-head clinical trials are still required to provide more information about the efficacy and safety of the two agents. In addition, other factors including adverse effects, patient preferences 


\section{A}

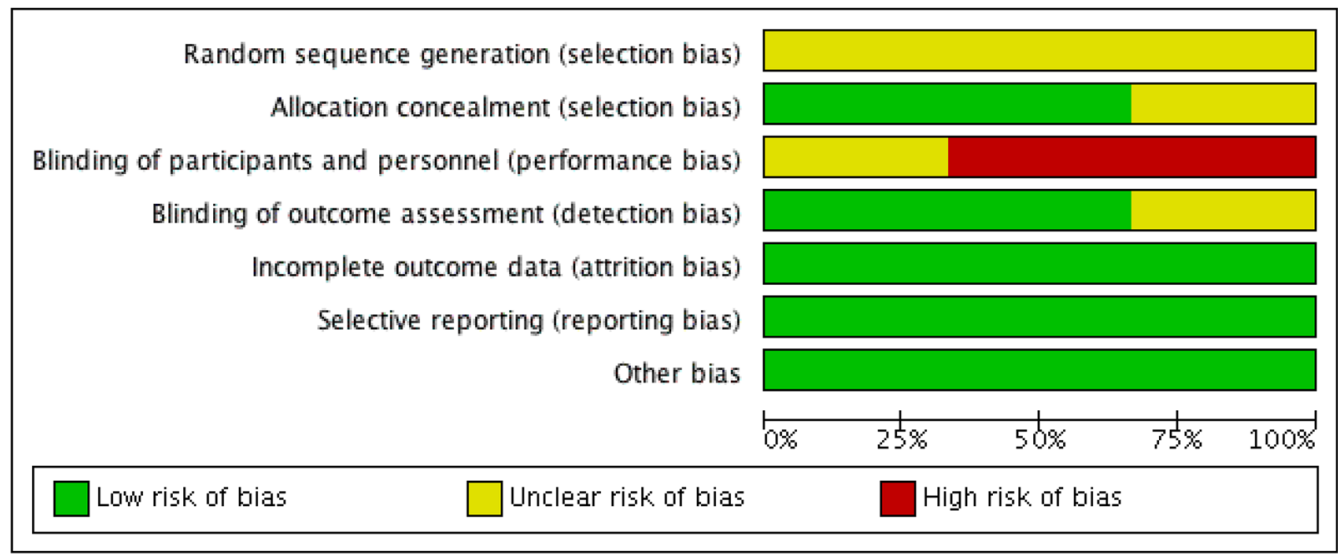

B

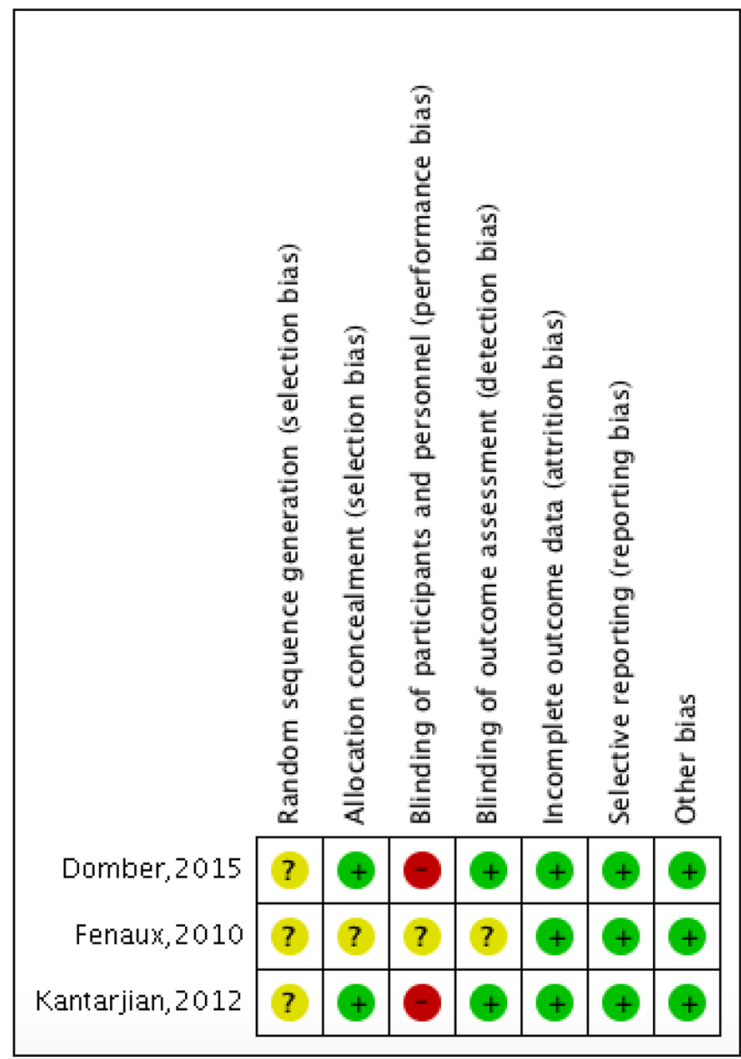

Fig. 5 a Risk of bias graph. b Risk of bias summary 
and cost, are also important and should be taken into consideration in the final choice between the two agents.

\section{Supplementary information}

Supplementary information accompanies this paper at https://doi. org/10.1186/s40164-020-00160-8.

Additional file 1: Figure S1. Azacitidine vs. conventional care regimens (direct evidence-RR). Figure S2. Azacitidine vs. conventional care regimens (direct evidence-OR). Figure S3. Decitabine vs. conventional care regimens (direct evidence-RR). Figure S4. Decitabine vs. conventional care regimens (direct evidence-OR). Table S1. Azacitidine compared to CCR for elderly patients diagnosed with AML. Table S2. Decitabine compared to CCR for elderly patients diagnosed with AML. Table S3. Azacitidine compared to decitabine for elderly patients diagnosed with AML. Table S4. Search strategies.

\section{Abbreviations}

HSCT: Hematopoietic stem cell transplantation; BSC: Best supportive care; CCR: Conventional care regimens; HMA: Hypomethylating agent; AML: Acute myeloid leukemia; RCT: Randomized controlled trial.

\section{Acknowledgements}

This work was grateful for Shenzhen Second People's Hospital.

\section{Authors' contributions}

$X D, B W$ and $W Y$ designed the study and collected and analysed the data. BW and WY conducted the search, collected the data, performed the analysis and wrote the manuscript. All authors critically revised the manuscript. All authors read and approved the final manuscript.

\section{Funding}

None.

\section{Availability of data and materials}

Not applicable.

\section{Ethics approval and consent to participate}

Not applicable.

\section{Consent for publication}

Not applicable.

\section{Competing interests}

The authors declare that they have no competing interests.

\section{Author details}

${ }^{1}$ Department of Internal Medicine, Shenzhen Second People's Hospital, The First Affiliated Hospital of Shenzhen University, Shenzhen 518000, China.

${ }^{2}$ Department of Hematology, Shenzhen Second People's Hospital, The First Affiliated Hospital of Shenzhen University, 3002 Sungang West Road, Futian District, Shenzhen 518000, China.

Received: 30 December 2019 Accepted: 27 February 2020 Published online: 16 March 2020

\section{References}

1. Arber DA. The 2016 WHO classification of acute myeloid leukemia: what the practicing clinician needs to know. Semin Hematol. 2019;56(2):90-5.

2. Siegel RL, Miller KD, Jemal A. Cancer statistics, 2018. CA Cancer JS Clin. 2018;68(1):7-30.

3. Siegel RL, Miller KD, Jemal A. Cancer statistics, 2019. CA Cancer J Clin. 2019:69(1):7-34.
4. Shallis RM, Wang R, Davidoff A, Ma X, Zeidan AM. Epidemiology of acute myeloid leukemia: recent progress and enduring challenges. Blood Rev. 2019. https://doi.org/10.1016/j.blre.2019.04.005.

5. Shysh AC, Nguyen LT, Guo M, Vaska M, Naugler C, Rashid-Kolvear F. The incidence of acute myeloid leukemia in Calgary, Alberta, Canada: a retrospective cohort study. BMC Public Health. 2017;18(1):94.

6. Ostgard LS, Norgaard JM, Severinsen MT, et al. Data quality in the Danish National Acute Leukemia Registry: a hematological data resource. Clin Epidemiol. 2013:5:335-44.

7. Juliusson G, Antunovic P, Derolf A, et al. Age and acute myeloid leukemia: real world data on decision to treat and outcomes from the Swedish Acute Leukemia Registry. Blood. 2009;113(18):4179-87.

8. Ocias LF, Larsen TS, Vestergaard H, Friis LS, Abildgaard N, Frederiksen $\mathrm{H}$. Trends in hematological cancer in the elderly in Denmark, 1980-2012. Acta oncologica (Stockholm, Sweden). 2016;55(Suppl 1):98-107.

9. Menzin J, Lang K, Earle CC, Kerney D, Mallick R. The outcomes and costs of acute myeloid leukemia among the elderly. Arch Intern Med. 2002;162(14):1597-603.

10. Lowenberg B, Downing JR, Burnett A. Acute myeloid leukemia. N Engl J Med. 1999:341(14):1051-62

11. Daly M, Paquette IM. Surveillance, epidemiology, and end results (SEER) and SEER-medicare databases: use in clinical research for improving colorectal cancer outcomes. Clin Colon Rectal Surg. 2019;32:61-8.

12. Dohner H, Estey EH, Amadori S, et al. Diagnosis and management of acute myeloid leukemia in adults: recommendations from an international expert panel, on behalf of the European LeukemiaNet. Blood. 2010;115(3):453-74

13. NCCN Clinical Practice Guidelines in Oncology Acute Myeloid Leukemia.

14. Santini V, Ossenkoppele GJ. Hypomethylating agents in the treatment of acute myeloid leukemia: a guide to optimal use. Crit Rev Oncol Hematol. 2019;140:1-7.

15. Fenaux P, Mufti GJ, Hellstrom-Lindberg E, et al. Azacitidine prolongs overall survival compared with conventional care regimens in elderly patients with low bone marrow blast count acute myeloid leukemia. J Clin Oncol. 2010;28(4):562-9.

16. Dombret H, Seymour JF, Butrym A, et al. International phase 3 study of azacitidine vs conventional care regimens in older patients with newly diagnosed AML with > 30\% blasts. Blood. 2015;126(3):291-9.

17. Kantarjian HM, Thomas XG, Dmoszynska A, et al. Multicenter, randomized, open-label, phase III trial of decitabine versus patient choice, with physician advice, of either supportive care or low-dose cytarabine for the treatment of older patients with newly diagnosed acute myeloid leukemia. J Clin Oncol. 2012;30(21):2670-7.

18. Moher D, Liberati A, Tetzlaff J, Altman DG. Preferred reporting items for systematic reviews and meta-analyses: the PRISMA statement. J Clin Epidemiol. 2009;62(10):1006-12

19. Murad MH. Clinical practice guidelines: a primer on development and dissemination. Mayo Clin Proc. 2017;92(3):423-33.

20. Murad MH, Montori VM, loannidis JPA, Prasad K, Cook DJ, Guyatt G. Fixedeffects and random-effects models. In: Users' guides to the medical literature: a manual for evidence-based clinical practice, 3rd ed. New York, NY: McGraw-Hill Education; 2015.

21. Glenny AM, Altman DG, Song F, et al. Indirect comparisons of competing interventions. Health Technol Assess. 2005;9(26):1-134.

22. Higgins JP, Jackson D, Barrett JK, Lu G, Ades AE, White IR. Consistency and inconsistency in network meta-analysis: concepts and models for multiarm studies. Res Synth Methods. 2012;3(2):98-110.

23. White IR, Barrett JK, Jackson D, Higgins JP. Consistency and inconsistency in network meta-analysis: model estimation using multivariate metaregression. Res Synth Methods. 2012;3(2):111-25.

24. Vachhani P, Al Yacoub R, Miller A, et al. Intensive chemotherapy vs. hypomethylating agents in older adults with newly diagnosed high-risk acute myeloid leukemia: a single center experience. Leukemia Res. 2018;75:29-35.

25. Kadia TM, Thomas XG, Dmoszynska A, et al. Decitabine improves outcomes in older patients with acute myeloid leukemia and higher blast counts. Am J Hematol. 2015;90(7):E139-41.

26. Boumber $\mathrm{Y}, \mathrm{Kantarjian} \mathrm{H}$, Jorgensen J, et al. A randomized study of decitabine versus conventional care for maintenance therapy in 
patients with acute myeloid leukemia in complete remission. Leukemia. 2012;26(11):2428-31.

27. Short NJ, Kantarjian HM, Loghavi S, et al. Treatment with a 5-day versus a 10-day schedule of decitabine in older patients with newly diagnosed acute myeloid leukaemia: a randomised phase 2 trial. Lancet Haematol. 2019;6(1):e29-37.

28. Seymour JF, Dohner H, Butrym A, et al. Azacitidine improves clinical outcomes in older patients with acute myeloid leukaemia with myelodysplasia-related changes compared with conventional care regimens. BMC Cancer. 2017;17(1):852.
29. Mehra M, He J, Potluri R, Loefgren C. Utilization of hypomethylating agents and associated outcomes in elderly acute myeloid leukemia (AML) patients: a population based study. Blood. 2017;130(Suppl 1):2157.

\section{Publisher's Note}

Springer Nature remains neutral with regard to jurisdictional claims in published maps and institutional affiliations.
Ready to submit your research? Choose BMC and benefit from:

- fast, convenient online submission

- thorough peer review by experienced researchers in your field

- rapid publication on acceptance

- support for research data, including large and complex data types

- gold Open Access which fosters wider collaboration and increased citations

- maximum visibility for your research: over $100 \mathrm{M}$ website views per year

At BMC, research is always in progress.

Learn more biomedcentral.com/submissions 